\title{
Total Laryngectomy with Horizontal Mechanical Closure of the Pharyngoesophagectomy: Evaluation of the Effectiveness in Elderly Patients
}

\author{
Eugenia Allegra ${ }^{10}$ Ignazio La Mantia ${ }^{2} \quad$ Alfio Azzolina ${ }^{3} \quad$ Massimo De Natale $^{3} \quad$ Serena Trapasso $^{1}$ \\ Vincenzo Saita ${ }^{3}$ \\ 1 Otolaryngology Unit, Department of Health Science, Magna Graecia \\ University of Catanzaro, Catanzaro, Italy \\ 2 Otolaryngology Unit, Santa Marta e Santa Venera Hospital, Acireale, \\ Catania, Italy \\ ${ }^{3}$ Otolaryngology Unit, Azienda Ospedaliera Cannizzaro, Catania, \\ Italy \\ Int Arch Otorhinolaryngol 2019;23:e338-e342. \\ Address for correspondence Eugenia Allegra MD, Otolaryngology \\ Unit, Department of Health Science, Magna Graecia University of \\ Catanzaro, Viale Europa, Germaneto, 88100, Catanzaro, Italy \\ (e-mail: eualle@unicz.it).
}

\begin{abstract}
Keywords

- total laryngectomy

- laryngeal cancer

- pharyngocutaneous fistula

Introduction The main modalities of surgical treatment for laryngeal cancer include transoral laser microsurgery (TLM), open preservation surgery, and total laryngectomy (TL). In the elderly, for the presence of comorbidities, the surgical approach more appropriate in many cases remains TL. The use of a stapler for the closure of the esophagus has been introduced to reduce surgical time and postoperative complications such as pharyngocutaneous fistula (PCF).

Objective In the present study, we have evaluated the effectiveness of the use of the horizontal mechanical pharyngoesophageal closure in patients who underwent TL.

Methods This nonrandomized study was performed on consecutive patients with histopathologically proven squamous cell endolaryngeal carcinoma. The TL was performed using a linear stapler to mechanically suture the pharyngotomy using the semiclosed technique. Results A total of 33 patients underwent TL, and 13 of them underwent neck dissection. A total of 15 patients (45.4\%) were $\leq 70$ years old, and 18 were $>70$ years old. Analyzing the results in relation to age, patients $>70$ years old showed tumors at an earlier stage than those aged $\leq 70$ years old. Furthermore, in this group there was a greater number of patients who had comorbidities $(p=0.014)$. In total, we had $2(6 \%)$ cases of PCF in $6.6 \%$ in the group $\leq 70$ years old, and in $5.5 \%$ of the group $>70$ years old $(p=1.00)$.

Conclusions The use of the stapler for the horizontal closure of the pharyngoesophagectomy in the patients subjected to TL is proven to be useful and safe even when used in elderly patients.
\end{abstract}

\section{Introduction}

Laryngeal cancer represents $4.5 \%$ of all malignancies and is one of the most common cancers of the upper aerodigestive tract. ${ }^{1}$

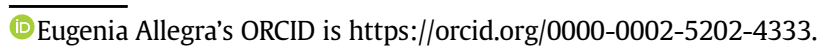

The main modalities of surgical treatment include transoral laser microsurgery (TLM), open preservation surgery (especially supracricoid laryngectomy), and total laryngectomy (TL). In the recent years, we have performed an increasing number of open preservation surgery, even in elderly patients, ${ }^{2}$ which can be attributed to the improvement of diagnostic approaches and to the improvement in received

March 2, 2018

accepted

February 13, 2019
DOI https://doi.org/

10.1055/s-0039-1685155. ISSN 1809-9777.
Copyright (e 2019 by Thieme Revinter

Publicações Ltda, Rio de Janeiro, Brazil
License terms

c) $(\oplus) \$$ 
the preoperative staging, ${ }^{3}$ but also to better living conditions for the elderly. However, until today, we have observed many patients with the advanced stage of the disease who needed a demolitive treatment. Also, simultaneously, there has been an increase in the average age of the patients who underwent a TL. This phenomenon is due to the increase of survival and, therefore, to the aging of the population. In the elderly, due to the presence of comorbidities, the surgical approach more appropriate in many cases remains a TL.

In 1971, for the first time, Lukyanchenko et $\mathrm{al}^{4}$ reported the use of a stapler for the closure of the esophagus to reduce surgical times and postoperative complications, such as pharyngocutaneous fistula (PCF).

Over time, the type of esophageal closure technique with a stapler has changed from the initial open technique to the semiclosed and closed techniques. However, the experiences reported in the literature are still scarce and nonunique, especially in relation to the appearance of PCF.

A PCF is a postoperative complication that increases the length of hospital stay and delays oral feeding. It may be a condition that severely compromises the health of the patient, especially when they are elderly with comorbidities.

In the present study, we report our experience with mechanical closure of pharyngoesophagectomy performing, for the first time with a stapler, a horizontal suture instead of a vertical suture. We perform the closure of the pharyngoesophagectomy with a horizontal suture, as reported by Shah et $\mathrm{al}^{5}$ because, in the semiclosed technique, a pharyngoesophagectomy that corresponds to the horizontal portion of the T-shaped manual suture of the traditional TL remains.

\section{Materials and Methods}

The present nonrandomized study was performed on consecutive patients with pathologically proven squamous cell endolaryngeal carcinoma.

The inclusion criteria for the patients were: endolaryngeal carcinoma with no extension to the suprahyoid epiglottis, to the pyriform sinus, and to the postcricoid extension, patients not eligible for transoral laser surgery or organ preservation surgery.

All of the patients were informed of the benefit, of the risks, and of the complications of this surgical technique and of its alternatives (radiotherapy or chemoradiotherapy) before they gave their informed consent.

The protocol was approved by the Institutional Review Board (IRB). All of the patients were preoperatively submitted to a computed tomography (CT) scan and to a microlaryngoscopy to confirm the extent of involvement of the tumor and to exclude laryngopharyngeal invading. The tumors were staged according to the 7th edition of the tumor node and metastasis (TNM) classification ${ }^{6}$ established by the American Joint Committee on Cancer. The TL was performed using a mechanical linear stapler for the pharyngoesophageal suture with the semiclosed technique. The neck dissection was performed according to the side and extension of the primary tumor and the Lymph nodal (N) clinical classification.

The demographics and clinical data of the patients, along with comorbidities, histopathology of the resection margins, nasogastric tube (NGT) removal time, length of hospitalization, and postoperative complications were collected.

\section{Surgical Technique}

One day prior to the surgery, a laryngoscopy was performed preoperatively in the office setting with a distal-chip flexible nasopharyngoscope Exera II (Olympus, Tokyo, Japan).

A traditional laryngectomy was performed in the initial steps. When the larynx was connected to the hypopharynx with the remaining thin mucosa-submucosa ( - Fig. 1) layer, a small pharyngoesophagectomy $(\sim 5 \mathrm{~mm})$ was performed along the median line at the level of suprahyoid region, and the free border of the epiglottis was pulled down using Allis pincers $20 \mathrm{~cm}$ (NGS Instruments) to avoid trapping part of the epiglottis between the jaws of the stapler. At this time, the larynx, hooking his tracheal termination, has been pulled upward and a mild tension on the hypopharynx mucosa was performed by an assistant and the stapler was inserted (- Fig. 2).

We have used for the present study the Proximate PLCLinear Cutter reusable stapler (Ethicon Inc., Somerville, NJ, USA), which affixes two double staggered rows of stitching in titanium, simultaneously passing a scalpel in the middle of the two rows. It was oriented with its open jaws horizontally (perpendicularly to the esophagus), then it was activated and 4 -fold rows of horizontal sutures line were performed (-Fig. 3). The larynx was removed and specimens were taken from the surgical margins to be evaluated extemporaneously. As traditionally, an intramuscular second suture

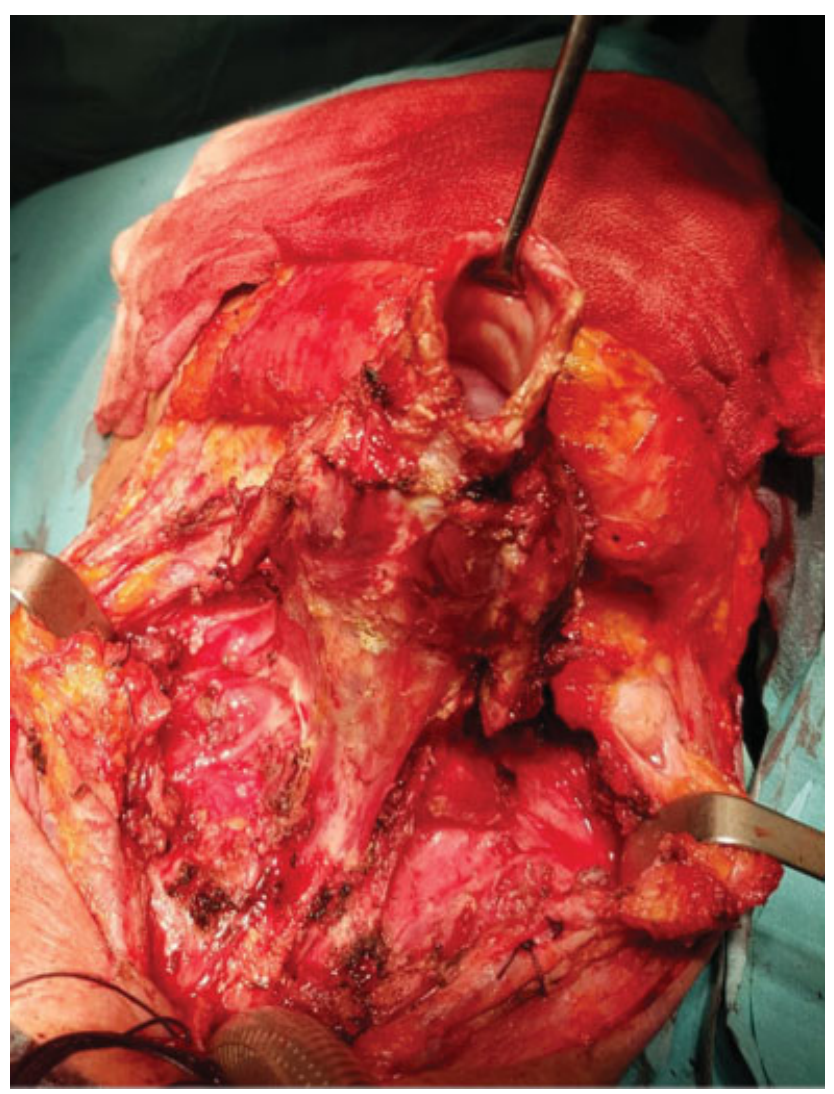

Fig. 1 Complete dissection of the larynx from the anterior wall of the esophagus. 


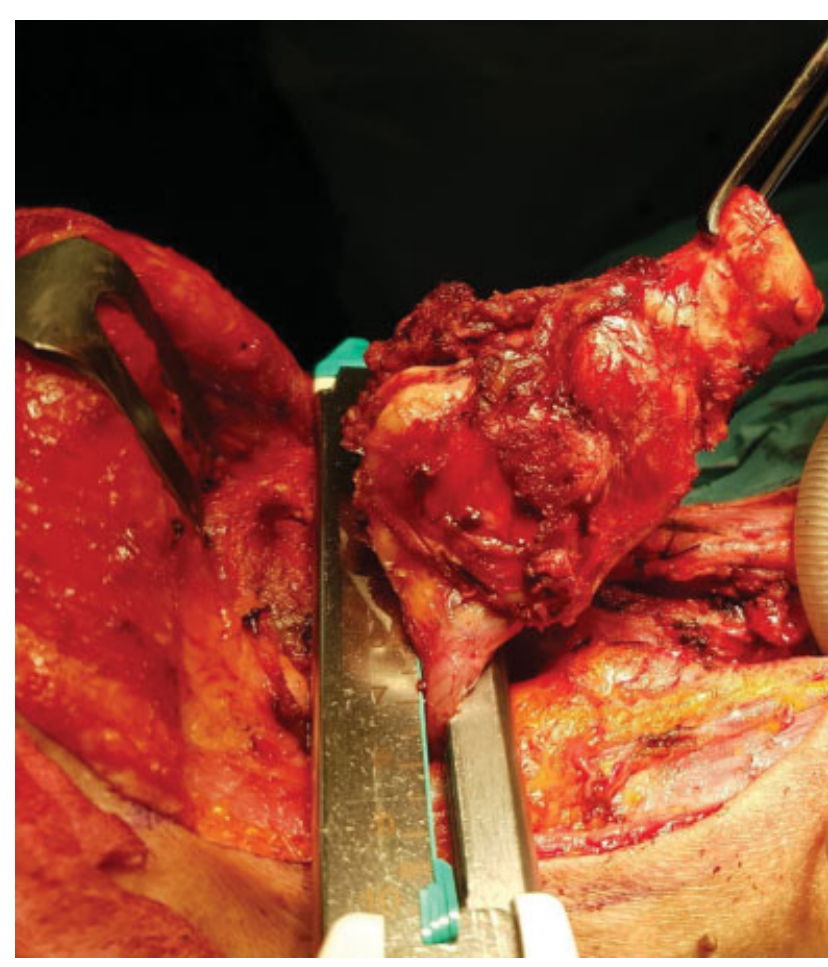

Fig. 2 Insertion of the linear stapler oriented with its open jaws horizontally (perpendicularly to the esophagus)

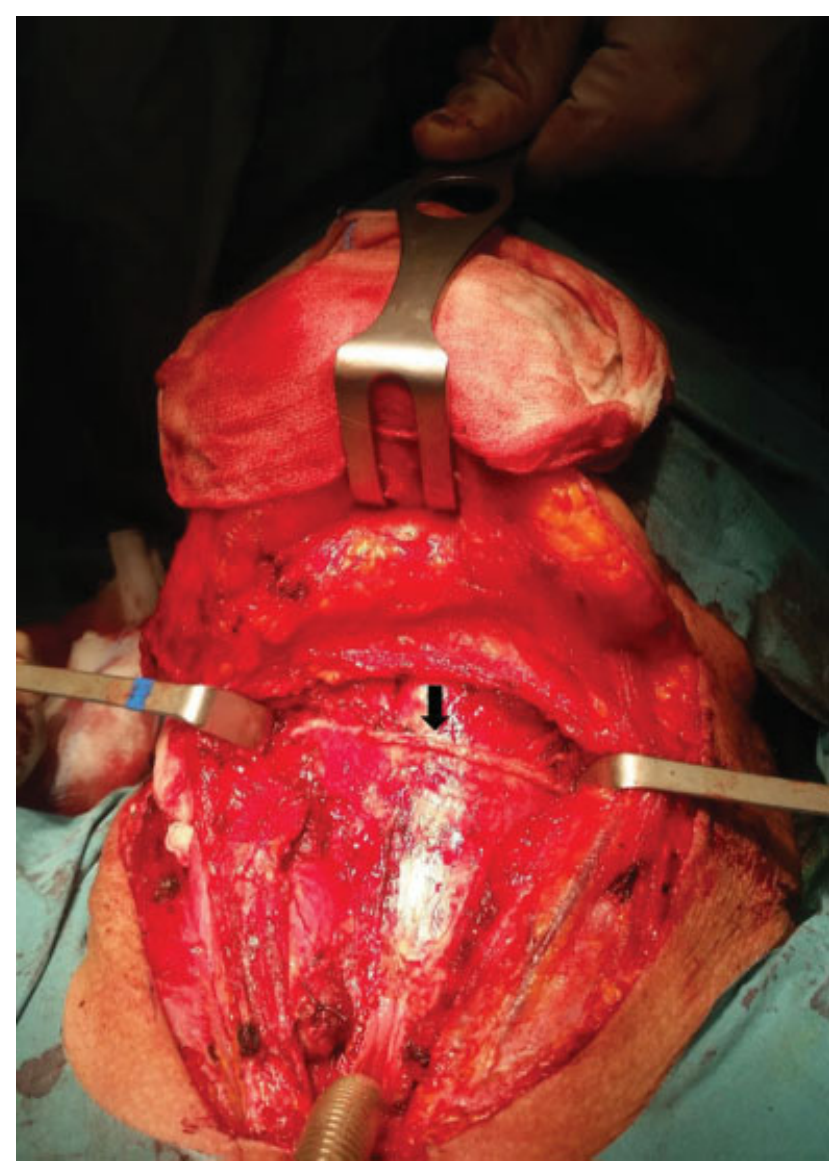

Fig. 3 Pharyngoesophageal closure realized with horizontal suture by the mechanical semiclosed technique. layer was made and a NGT feeding tube was introduced when the TL was completed.

\section{Statistical Analysis}

Statistical analysis was performed with the MedCalc software (MedCalc Software, Ostend, Belgium) using the chi-squared test and the Fisher exact test. The Mann-Whitney test and the independent sample t-test were used to compare age, NGT feeding tube removal time, and length of hospitalization. All pvalues are two-tailed, and $p<0.05$ was considered significant.

\section{Results}

A total of 33 TLs were performed between 2014 and 2017 at the Otolaryngology Unit, Azienda Ospedaliera Cannizzaro, Catania, Italy, using the linear stapler for pharyngoesophageal closure.

Out of the total sample, 31 patients were male, and 2 were female. Their age ranged from 48 to 84 years old (mean \pm standard deviation $[S D]: 69.3 \pm 9.4$; median $=72.8$ ). According to the TNM classification, 6 cases were classified as T1bN0, 6 as T2N0, 1 as T2N1, 8 as T3N0, 4 as T3N1, 1 as T3N2, 3 as T4N0, 3 as T4N1, and 1 as T4N2. Out of the total 33 patients, 13(39.3\%) underwent selective or modified neck dissection, 5 underwent ipsilateral selective neck dissection, 5 underwent bilateral selective neck dissection, 3 underwent modified neck dissection and contralateral selective neck dissection, and 7 of the 33 patients were not submitted to neck dissection. A total of 5 patients presented with metastatic lymph nodes and were treated with radiotherapy. A total of 15 patients (45.4\%) were $\leq 70$ years old, and 18 were $>70$ years old. Analyzing the results in relation to age ( - Table 1 ), $3(20 \%)$ of the 15 patients $\leq 70$ years old, and 10 (55.5\%) of those aged $>70$ years old presented with tumors at an early stage (T1-T2) $(p=0.07)$, All of the T1-T2 classified tumors were previously treated. In the group of younger patients, 4 had been previously treated with radiation therapy ( 1 case) or with TLM ( 3 cases), while in the group of older patients, 9 had been previously treated with radiation therapy ( 6 cases) or with TLM ( 3 cases). Comorbidities were present in 4 of the 15 younger patients ( 3 hypertension, 1 psychiatric illness), and in 13 of 18 elderly patients (3 hypertension, 4 diabetes, 1 renal infarction, 1 pulmonary emphysema, 2 hepatopathy, and 2 hypertension and diabetes). The elderly group had more comorbidities, which was statistically significant ( $p=0.014)$. We found complications in 2 of the younger patients; one of them had comorbidities. In older patients, a complication occurred in 4 of the 13 with comorbidities. In the group of younger patients, the complications were postsurgically related (1 postsurgical bleeding and 1 PCT); while, in the elderly, 2 out of 4 were surgery-related, while 2 were systemic complications ( 1 intestinal infarction, 1 postsurgical bleeding, 1 renal failure, 1 PCF). The occurrence of surgery-related complications was not significantly different in the two groups (- Table 2 ). The removal time of the NGT tube was of $6.8 \pm 0.4$ and of $7.8 \pm 0.6$ days in the younger and older patients, respectively ( $p=0.086$ ). The time of hospitalization was higher in the group of elderly patients ( $8.4 \pm 0.5$ versus $9.9 \pm 1.6$ days, $p=0.052$ ), mainly due to comorbidities. 
Table 1 Comparison of data between patients $\leq 70$ and $>70$ years old

\begin{tabular}{|c|c|c|c|}
\hline $\begin{array}{l}\text { Data of the } \\
\text { Patients }\end{array}$ & $\begin{array}{l}\leq 70 \text { years } \\
\text { old }(n=15)\end{array}$ & $\begin{array}{l}>70 \text { years } \\
\text { old }(n=18)\end{array}$ & $p$-value \\
\hline \multicolumn{3}{|l|}{ Age } & \multirow[t]{2}{*}{$<0.001$} \\
\hline $\begin{array}{l}\text { mean } \pm S D \\
\text { (years old) }\end{array}$ & $58.7 \pm 5.6$ & $77.2 \pm 4.4$ & \\
\hline \multicolumn{3}{|l|}{ T status } & \multirow[t]{3}{*}{0.007} \\
\hline T1-T2 & $3(23 \%)$ & $10(77 \%)$ & \\
\hline T3-T4 & $12(60 \%)$ & $8(40 \%)$ & \\
\hline \multicolumn{3}{|l|}{$\mathrm{N}$ status } & \multirow[t]{3}{*}{0.12} \\
\hline NO & $8(34.8 \%)$ & 15 (65.2\%) & \\
\hline $\mathrm{N}+$ & 7 (70\%) & $3(30 \%)$ & \\
\hline \multicolumn{3}{|l|}{ Neck dissection } & \multirow[t]{3}{*}{0.16} \\
\hline No & 7 (35\%) & 13 (65\%) & \\
\hline Yes & $8(61.5 \%)$ & $5(38.5 \%)$ & \\
\hline \multicolumn{3}{|l|}{ Comorbidities } & \multirow[t]{3}{*}{0.014} \\
\hline No & 11 (68.8\%) & $5(31.2 \%)$ & \\
\hline Yes & $4(23.5 \%)$ & $13(76.5 \%)$ & \\
\hline \multicolumn{3}{|l|}{ Complications } & \multirow[t]{3}{*}{0.66} \\
\hline No & $13(48.1 \%)$ & $14(51.9 \%)$ & \\
\hline Yes & $2(33.3 \%)$ & $4(66.7 \%)$ & \\
\hline $\begin{array}{l}\text { NGFTR time } \\
\text { Mean } \pm \text { SD (days) }\end{array}$ & $6.8 \pm 0.5$ & $7.8 \pm 0.6$ & 0.086 \\
\hline $\begin{array}{l}\text { Length of } \\
\text { hospitalization } \\
\text { mean } \pm S D \text { (days) }\end{array}$ & $8.6 \pm 0.5$ & $9.7 \pm 1.6$ & 0.052 \\
\hline
\end{tabular}

Abbreviation: NGFTR, Naso-gastric-feeding Tube removal; N, Node; SD, standard deviation; T, Tumor.

Table 2 Correlation between comorbidities and postsurgical complications in the two groups

\begin{tabular}{|l|l|l|}
\hline Patients & $\begin{array}{l}\text { PSC } \\
n(\%)\end{array}$ & $\begin{array}{l}\text { No PSC } \\
n(\%)\end{array}$ \\
\hline $\begin{array}{l}\leq 70 \text { years old } \\
\boldsymbol{n}=15\end{array}$ & $1(25 \%)$ & $3(75 \%)$ \\
\hline $\begin{array}{l}>70 \text { years old } \\
n=18\end{array}$ & $2(15.4 \%)$ & $11(84.6 \%)$ \\
\hline$p$-value & 1.00 & \\
\hline
\end{tabular}

Abbreviation: PSC, postsurgical complications.

*Fisher exact test.

\section{Discussion}

The use of staplers in head and neck surgery was introduced late in relation to in thoracic, abdominal, and gynecological surgery. However, although it has already been introduced for 40 years for the closure of pharyngoesophagectomy in patients undergoing TL, it has not yet had a wide acceptance. Studies published during these years are still few and heterogeneous regarding the type of staplers used, the pharyngoesophagectomy closing techniques, and the indication for TL (primary or salvage after radiotherapy). Our study, like other studies, ${ }^{7,8}$ include patients in the early tumor stages; however, in the early tumor stage, most of these our patients were elderly patients were elderly. This difference can be attributed to the fact that we prefer to treat early laryngeal cancers and local recurrence with conservative treatments (endoscopic surgery or open surgery), and reserve TL or radiotherapy only for cases that cannot benefit from further conservative treatment (TLM) or organ preservation surgery, as supracricoid laryngectomy. It is known that older subjects are less eligible for organ preservation surgery because of the greater difficulties they present in postsurgical rehabilitation. A greater number of older patients in our experience had comorbidities ( $p=0.014$ ). However, we did not encounter a significant difference in terms of the appearance of postsurgical complications in the two groups of patients. The appearance of PCT represents the most frequent postsurgical complication after TL. Therefore, it constitutes one of the most used parameters for the evaluation of the effectiveness of the use of the stapler. According to some authors, the appearance of PCF after TL with stapler ranges from 0 to14\%, ${ }^{9-14}$ while other authors reported incidences of $26.7 \%$ and of $30 \%{ }^{7,8,15}$ A PCF appeared in $6 \%$ of the total 33 patients in our sample. The highest percentage of PCFs observed by Dedivitis et $\mathrm{al}^{7}$ and by Babu et $\mathrm{al}^{8}{ }^{8}$ compared with ours, may be due to the fact that in $75 \%^{7}$ and in $70 \%^{8}$ of these cases, the laryngectomies were of salvage after radiotherapy, while in our study only $22 \%$ of the patients had previously been treated with radiotherapy. An important aspect of postsurgical outcome after TL is the average time of removal of the NGT tube, that is, the time elapsed until returning the patients to their normal oral feeding from the day of surgery. The removal time of the NGT tube after TL with mechanical suture is reported by few authors. ${ }^{11,15}$ In our experience, we have found a median time of removal of NGT tube similar to those reported by Altissimi et al ${ }^{11}$ and by Zhang et al. ${ }^{16}$

The average length of hospitalization depends mainly on the occurrence of postoperative complications (PCF, surgical wound infections, systemic complications). The mean duration of hospitalization after TL with a stapler is reported only by Paddle et al $^{17}$ (median time: 6 days). We have analyzed our results considering the age of the patients and found no statistically significant differences with regard to the removal time of the NGT tube and hospitalization time, despite a difference in the presence of comorbidities.

An increase in the duration of surgery exposes patients to more intra- and postoperative complications in relation to the increase of the duration of the anesthesia, especially in the elderly. Turrentine et $\mathrm{al}^{18}$ showed that an increase in 30 minutes in the duration of the surgery increases the odds of death by $17 \%$ in patients aged $>80$ years old. ${ }^{17}$ The closure of pharyngoesophagectomy with stapler takes $\sim 5$ minutes, while manual closing takes much longer, and its duration is relative to the experience of the surgeon. According to some authors, ${ }^{15,19}$ the stapler reduces the duration of the surgery in $\sim$ between 45 and 80 minutes. All of the previous studies, excluding the one by Dedivitis et al, ${ }^{7}$ despite their lack of homogeneity, reported a benefit in reducing the appearance 
of PCF in patients who underwent TL with the closure of the pharyngoesophagectomy with a stapler. The appearance of postsurgical complications can put at risk the survival of the patient, mainly in the elderly. The delay of the beginning of an adequate oral feeding, and the need to prolong the antibiotic therapy due to the risk of the PCF, may irreversibly impair the health condition of the patient.

The closure of pharyngotomy with horizontal mechanical suture avoids the weakest critical point of the vertical suture represented by the trifurcation point. With this technique, no opening of the esophagus occurs because the larynx is unglued posteriorly, saving the anterior wall of the esophagus. Furthermore, it reduces the contact surface between the NGT tube and the suture.

Conditions, which would reduce the risk of postsurgical complications and a faster recovery. However, the technique has some limitations represented by the fact that it can be used in a restricted number of patients with endolaryngeal cancer.

\section{Conclusions}

The use of the stapler for the horizontal closure of the pharyngotomy in patients subjected to TL proved to be useful and safe even when used in elderly patients not eligible for further conservative treatment.

Conflicts of Interest

The authors have no conflicts of interest to declare.

\section{References}

1 Parkin DM, Bray F, Ferlay J, Pisani P. Global cancer statistics, 2002. CA Cancer J Clin 2005;55(02):74-108

2 Allegra E, Ferrise P, Trapasso S, et al. Early glottic cancer: role of MRI in the preoperative staging. BioMed Res Int 2014;2014:890385

3 Allegra E, Franco T, Trapasso S, Domanico R, La Boria A, Garozzo A. Modified supracricoid laryngectomy: oncological and functional outcomes in the elderly. Clin Interv Aging 2012;7:475-480

4 Luk'yanchenko AG. Suturing of a laryngeal defect in laryngotomy. Vestn Otolaryngol 1971;33:29-30
5 Shah JP, Patel SG. Head and Neck Surgery and Oncology (Third Edition). Mosby; 2003

6 Sobin LH, Gospodarowicz MK, Wittekind C. TNM classification of Malignant tumours, 7th ed. Oxford, UK: Wiley-Blackwell; 2009

7 Dedivitis RA, Ribeiro KC, Castro MA, Nascimento PC. Pharyngocutaneous fistula following total laryngectomy. Acta Otorhinolaryngol Ital 2007;27(01):2-5

8 Babu S, Varghese BT, lype EM, George PS, Sebastian P. Evaluation of stapled closure following laryngectomy for carcinoma larynx in an Indian tertiary cancer centre. Indian J Cancer 2015;52(03): 376-380

9 Simoncelli C, Altissimi G. [Mechanical sutures of the pharynx during total laryngectomy: proposal of a closed technique]. Acta Otorhinolaryngol Ital 1990;10(05):465-474

10 Bedrin L, Ginsburg G, Horowitz Z, Talmi YP. 25-year experience of using a linear stapler in laryngectomy. Head Neck 2005;27(12): 1073-1079

11 Altissimi G, Frenguelli A. Linear stapler closure of the pharynx during total laryngectomy: a 15-year experience (from closed technique to semi-closed technique). Acta Otorhinolaryngol Ital 2007;27(03):118-122

12 Ahsan F, Ah-See KW, Hussain A. Stapled closed technique for laryngectomy and pharyngeal repair. J Laryngol Otol 2008;122 (11):1245-1248

13 Sofferman RA, Voronetsky I. Use of the linear stapler for pharyngoesophageal closure after total laryngectomy. Laryngoscope 2000;110(08):1406-1409

14 Gonçalves AJ, de Souza JA Jr, Menezes MB, Kavabata NK, Suehara $A B$, Lehn $C N$. Pharyngocutaneous fistulae following total laryngectomy comparison between manual and mechanical sutures. Eur Arch Otorhinolaryngol 2009;266(11):1793-1798

15 Santaolalla Montoya F, Ruiz de Galarreta JC, Sánchez del Rey A, Martínez Ibargüen A, Zabala López de Maturana A. [Comparative study of the use of manual and mechanical suturing in the closure of the mucosal defect in total laryngectomy]. Acta Otorrinolaringol Esp 2002;53(05):343-350

16 Zhang X, Liu Z, Li Q et al. Using a linear stapler for pharyngeal closure in total laryngectomy. Eur Arch Otorhinolaryngol 2013; 270(04):1467-1471

17 Paddle P, Husain I, McHugh L, Franco R Jr. Outcomes of mechanical stapling for postlaryngectomy open pharyngotomy closure. Laryngoscope 2017;127(03):605-610

18 Turrentine FE, Wang H, Simpson VB, Jones RS. Surgical risk factors, morbidity, and mortality in elderly patients. J Am Coll Surg 2006; 203(06):865-877

19 Ismi O, Unal M, Vayisoglu Y, et al. Stapler Esophageal Closure During Total Laryngectomy. J Craniofac Surg 2017;28(01):e35-e40 